FJARD VOL. 35, NO. 2. PP. 391-401(2021)

Fayoum Journal of Agricultural Research
and Development
ISSN:1110-7790

\title{
Determinants of food security for animal protein from fish, milk and their products in Egypt
}

\author{
Ahmed Zedan \\ Researcher - Agricultural Economics Research Institute - Agricultural Research Center \\ محدات الأمن الغذائى للبروتين الحيوانى من الأسماك والألبان ومنتجاتها فى مصر - Rر
}

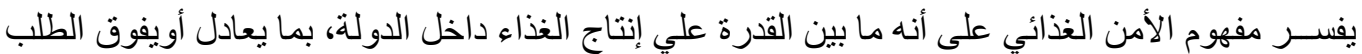

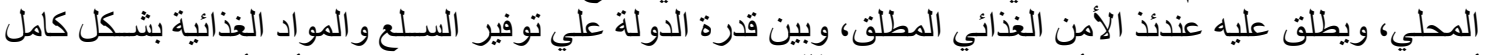

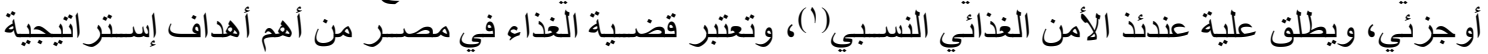

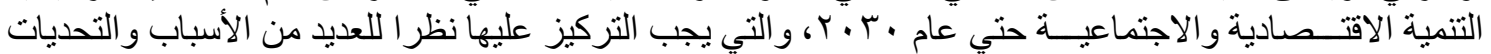

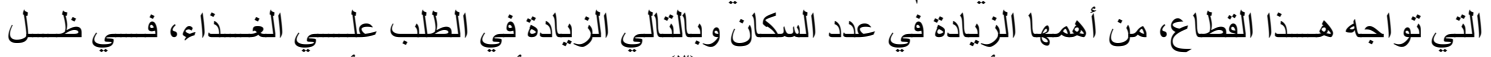

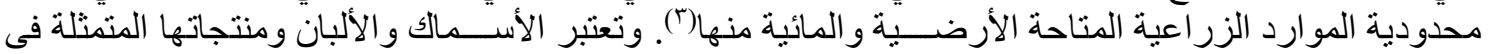

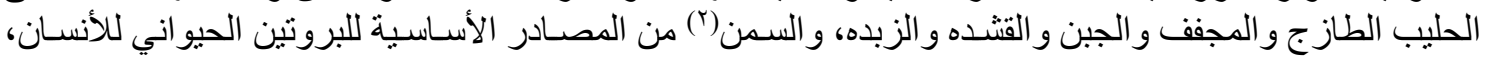

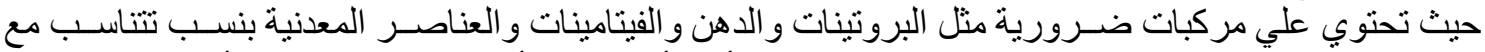

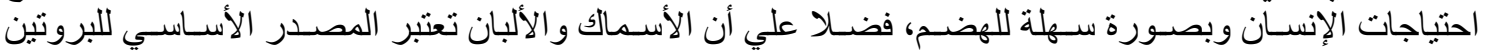

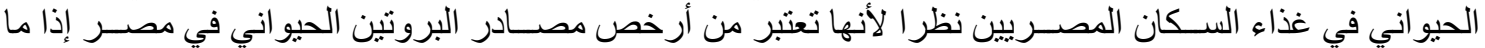

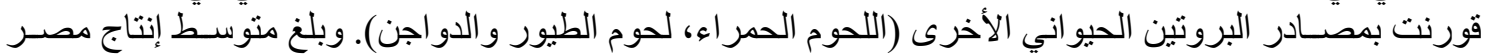

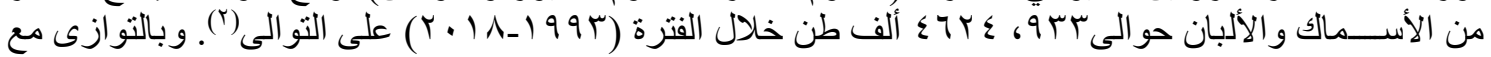

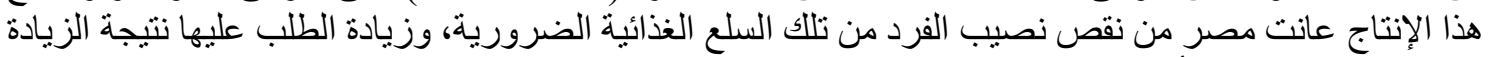

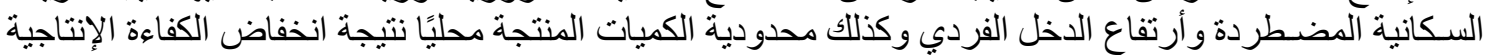

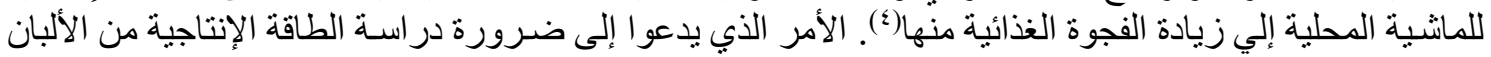

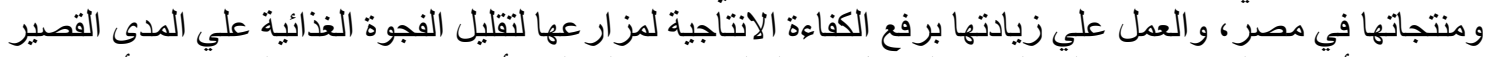

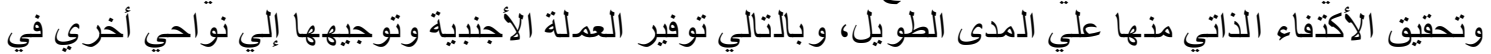

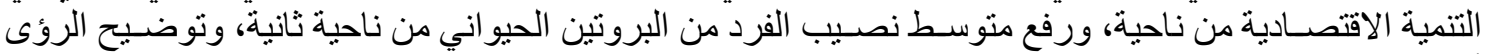

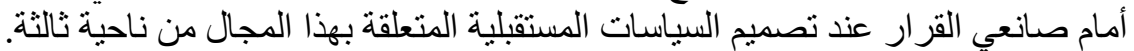

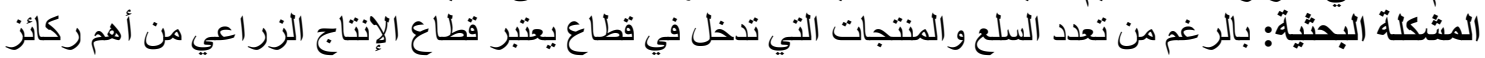

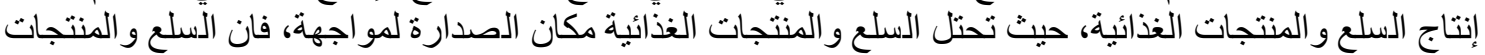

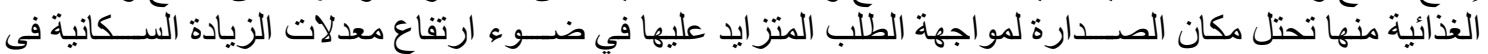

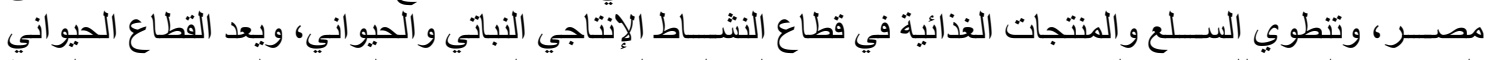

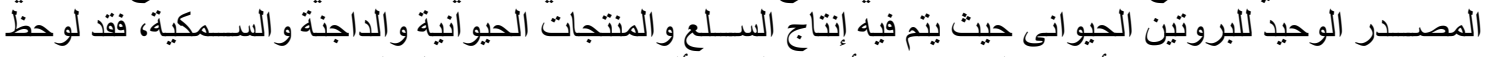

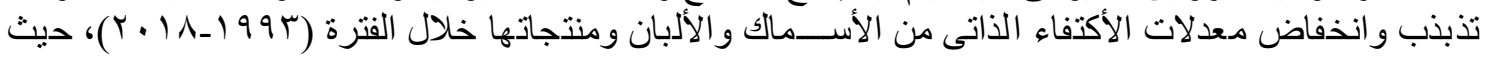

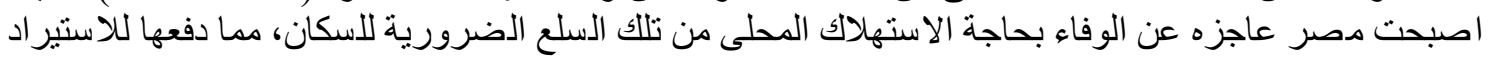
من الخارج لسد الفجوة الغذائية من البروتين الحيوانى.

Received: 20/4/ 2021

Accepted: 4/5/ 2021 

وقد توصلت الاراسة لأهم النتائج التالية:

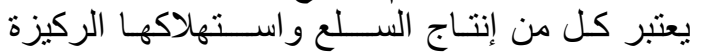

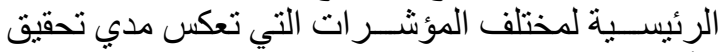

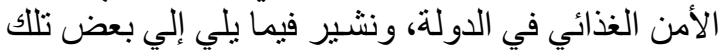

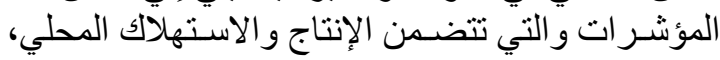

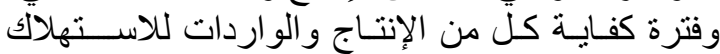

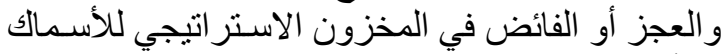

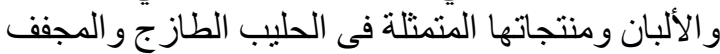

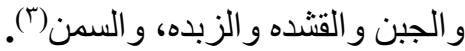

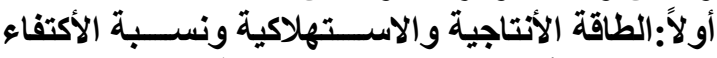
الذاتى من الأسماك وتجارتها الألها الخارجية فى مصر: 1- كمية إنتاج الأسماك فى مصر الأنى

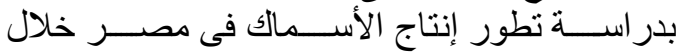

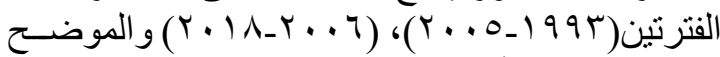

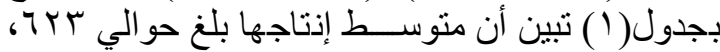

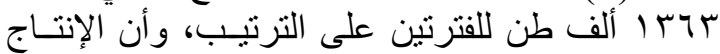

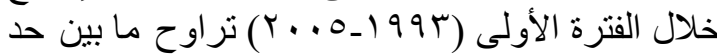

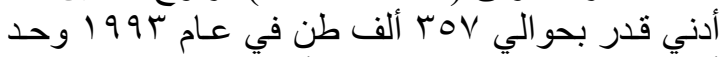

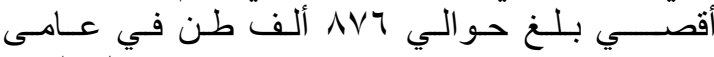

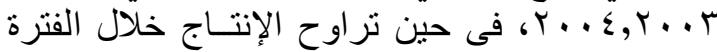

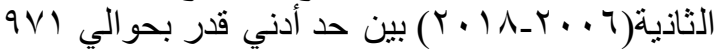

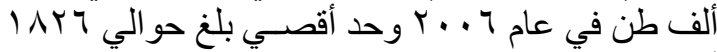

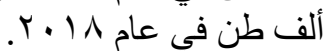
وبتقدير معادلات الأتجاه الزمني العام لإنتاج الأسماك

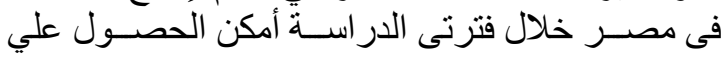

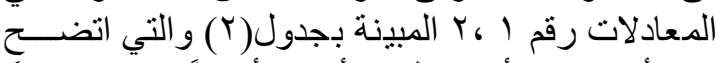

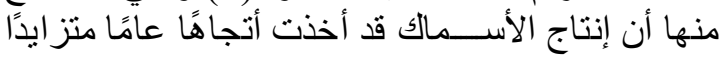

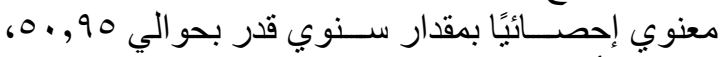

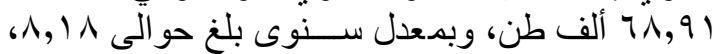

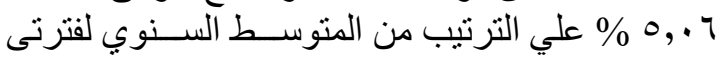

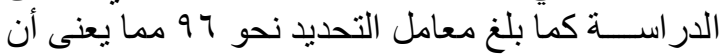

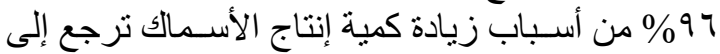

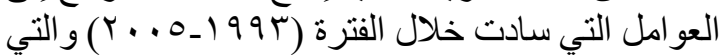

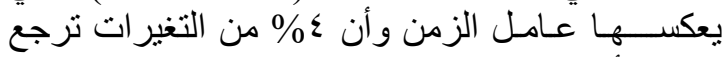

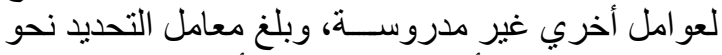

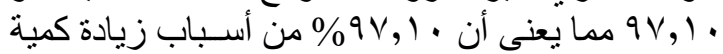

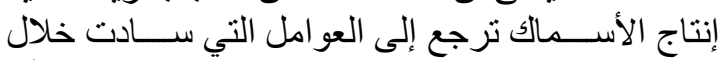

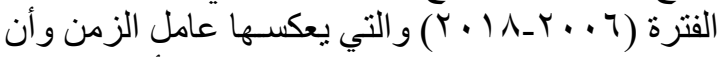

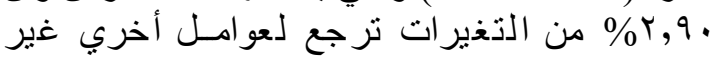
مدروسة.

r-كمية الصادرات والواردات من الأسماك فى مصر:

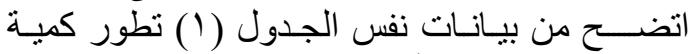

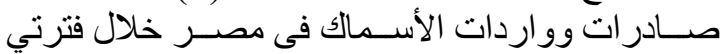

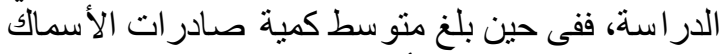

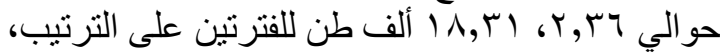

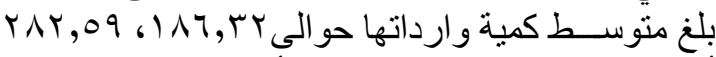

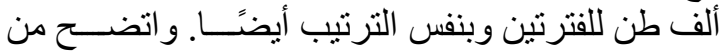

الأهداف البحثية: يهذف البحث إلي الوقوف علي الوضع

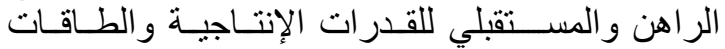

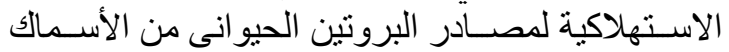

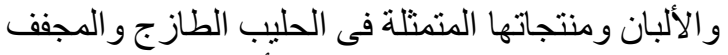

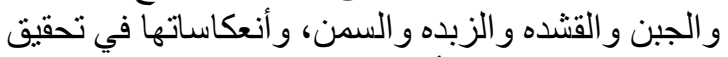

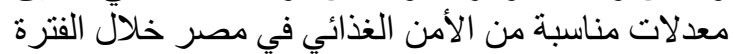

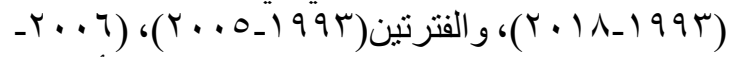

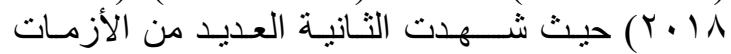
الاقتصادية، وذللك من خلال تحقيق الأهداف التالية:

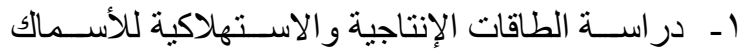
و الألبان ومنتجاتها وتجارنها الانتية الخارجية، وتوقعاتها

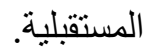
r- در اســة وتحديد معدلات الأكتفاء الذاتي من الأسـماك و الألبان وتوقعاتها المستقبلية.

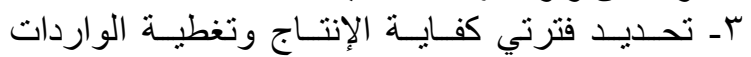

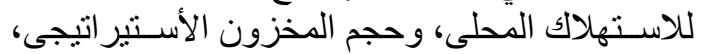

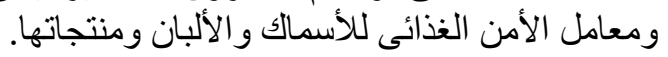

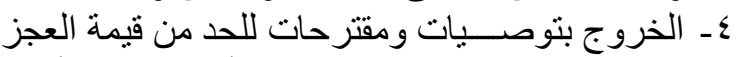

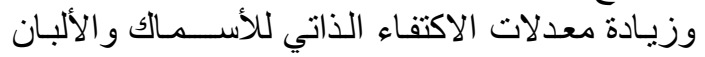

$$
\text { ومنتجاتها. }
$$

$$
\text { مصادر البيانات والأسلوب البحثي: }
$$

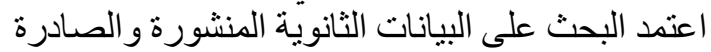

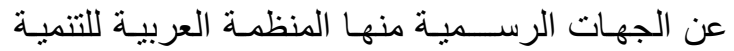

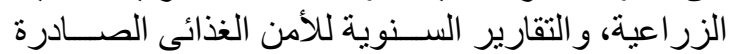

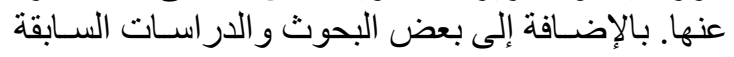

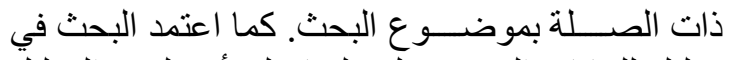

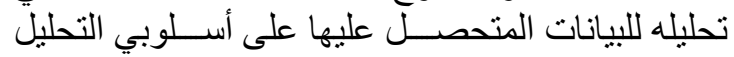

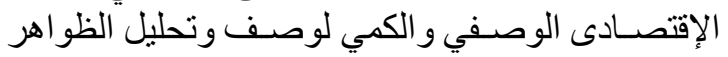

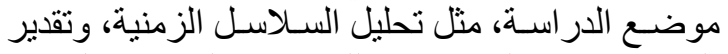

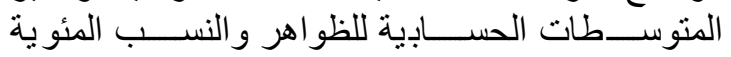

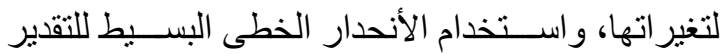

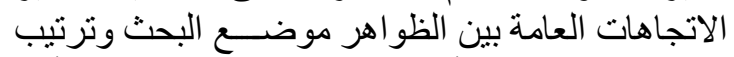

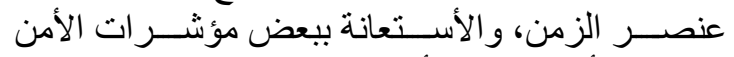

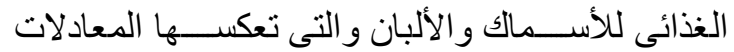

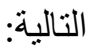
ـ الاسـتهلاك المحلي اليومي= إجمالي الاسـتهلاك المحلي .

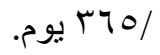
• فترة كفاية الإنتاج للاســــلالكأك= إجمالي الإنتاج المحلي

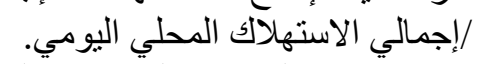

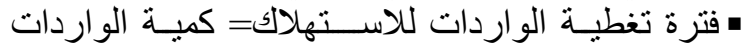

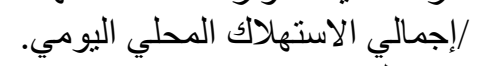

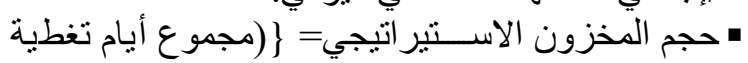

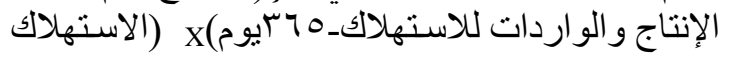

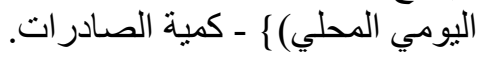

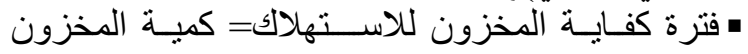

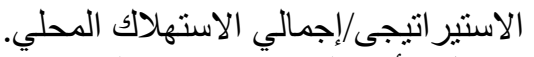

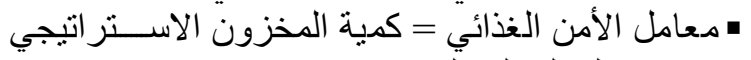
/الاستهلاك المحلي الَّنوي. 
معادلات الأتجاه الزمني العام رقم ب ، ؛ ،0 ، 7 المبينة مصر خلال الفترة الثانية من الدر اسة أخذت أتجاهًا عامًا

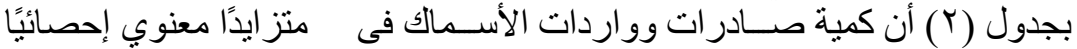

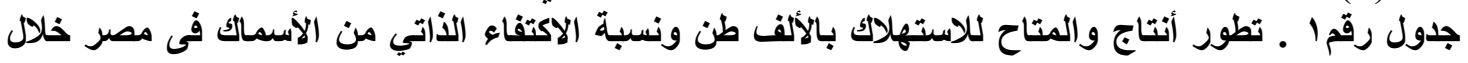

\begin{tabular}{|c|c|c|c|c|c|}
\hline نسبة الاكتفاء & لاستهالكاحك & الوارداتة & الصمادرّاتة & الانتاج & السنوات \\
\hline Vะ, V & $\varepsilon \wedge Y$ & IYV,qA & $r, q r$ & TOV & 1994 \\
\hline$V Y, Y$. & 01. & $1 \varepsilon \varepsilon, V T$ & T,AV & M M & 1995 \\
\hline$V V, Y q$ & orv & $|r|, \leqslant q$ & 1,10 & $\varepsilon \cdot V$ & 1990 \\
\hline TY,T & $7 \wedge 9$ & 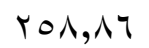 & $1,7 \leq$ & (Tr & 1997 \\
\hline$V_{0}, \leqslant 1$ & 7.7 & 10.,人 & $1, \wedge r$ & $\leqslant 0 V$ & 1998 \\
\hline VT, IT & $V \leqslant 7$ & $r \ldots, \vee v T$ &., 09 & $0 \leqslant 7$ & 1991 \\
\hline$\vee 0, v \leqslant$ & NOV & $r \cdot \Lambda, r_{0}$ & q & $7 \leqslant 9$ & 1999 \\
\hline$V V, 0$. & $q u v$ & חז,חוץ &., 97 & VY & $r \ldots$ \\
\hline$V \varepsilon, 7)$ & 1.49 & 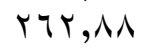 & $1, \leqslant 7$ & VTA & $r . .1$ \\
\hline$\wedge \mu, \leqslant q$ & $q r$. & ه & r,or & VTA & $r \ldots r$ \\
\hline$\Lambda \varepsilon, O V$ & דr 1. & $17 \pi, .1$ & r & $\Lambda \vee T$ & $r . . r$ \\
\hline$\vee q, \vee$. & $1.9 V$ & qr, & $0,0$. & $\Lambda \vee T$ & $r \ldots \varepsilon$ \\
\hline$\Lambda T, \leqslant T$ & $1 \cdot \leqslant 9$ & $1 \wedge 9, \ldots$ & $0, \ldots$ & 170 & r... 0 \\
\hline V T, rV & $\Lambda \cdot V$ & IA7,r & דr, & TYT & المتوسط \\
\hline$\Lambda \cdot, \leqslant \leqslant$ & $M \cdot V$ & $r r q, \wedge v$ & $\varepsilon, .0$ & $9 \times 1$ & $r \ldots T$ \\
\hline גז, & IYYE & סָ, • r & $\varepsilon,{ }^{\prime}$ & $1 \cdots 1$ & $r \ldots r$ \\
\hline سז, & $|r \wedge|$ & ס , . r & $7, V T$ & 1.71 & $r . \lambda$ \\
\hline AV,r & I ror & 178,89 & $\mathrm{~V}, \mathrm{VO}$ & 1.94 & $r . . q$ \\
\hline$\wedge q, \Gamma \wedge$ & $1 \leq 7$. & $1 \vee \leqslant, \wedge 0$ & $19,0$. & $1 T .0$ & r. I. \\
\hline$\wedge 9, \cdot \wedge$ & 1049 & IVA, IT & $1 \cdot, \wedge$. & rדו & 4.11 \\
\hline$\Lambda T, 7 r$ & $101 \varepsilon$ & Y Y $\varepsilon, O Q$ & $1 T, .7$ & ITVT & $r .1 T$ \\
\hline$\Lambda \vee, \Lambda$. & 1077 & r,r,r & $1 Y, .7$ & I TVo & r. \\
\hline$v_{0,0}$. & $197 \varepsilon$ & $010,1$. & • ו & $1 \leq \Lambda r$ & $r .1 \leq$ \\
\hline$V T, Y$. & 1994 & $\leqslant 97,9$. & $r r, \Lambda$. & 1019 & $r .10$ \\
\hline ᄉ & $19 Y \varepsilon$ & Tor,r. & $\varepsilon \ldots, \ldots$ & 1714 & $r .17$ \\
\hline$\wedge 7,9$. & 1917 & $r q \varepsilon, 1$. & Tะ, $\varepsilon$. & IVYT & r. IV \\
\hline$\wedge \Vdash, \nearrow \wedge$ & $r \wedge r$ & 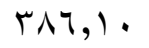 & $r, \xi \leqslant$ & $1 \wedge r t$ & r.11 \\
\hline$\Lambda \varepsilon, \cdot r$ & $17 r V$ & $r \wedge r, \diamond q$ & $|\Lambda, r|$ & rq"1 & المتوسط \\
\hline
\end{tabular}




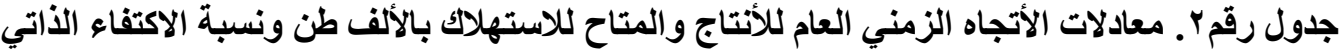

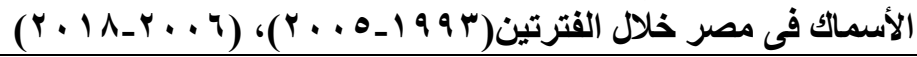

\begin{tabular}{|c|c|c|c|c|c|c|c|c|}
\hline \multirow[b]{2}{*}{ ف } & \multicolumn{4}{|c|}{ متوسط التغير } & \multirow[b]{2}{*}{ النموذج } & \multirow[b]{2}{*}{ s } & \multirow{2}{*}{ الفترة } & \multirow[b]{2}{*}{ 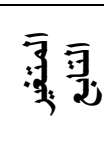 } \\
\hline & Y & $\begin{array}{l}\text { المئوى } \\
\text { (\%) }\end{array}$ & (ألف طمي) & المتوسط & & & & \\
\hline **YTo,Ar &., $97 \ldots$ & $\lambda, \wedge$ & $0 ., 90$ & אזד & 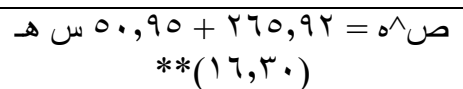 & 1 & الأولى & \\
\hline$* * r v \cdot, 1 r$ & .,9マ1. & $0, .7$ & $7 \wedge, 91$ & 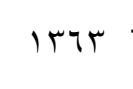 & 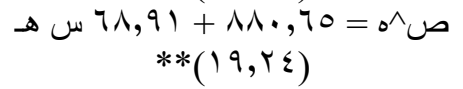 & r & الثانية & th \\
\hline$r, \wedge q$ & $\cdot, r \cdot \Lambda$. & $v, v)$ & $\cdot, \lambda r$ & r, ru & 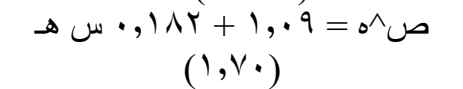 & $r$ & الأولى & $\overline{7}$ \\
\hline **rч, $\vee r$ &.,$\vee>9$. & $10, \leqslant 7$ & $r, \wedge r$ & $|\lambda, \mu|$ & 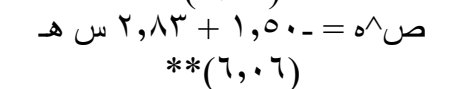 & $\varepsilon$ & الثانية & $\frac{3}{\sqrt{3}}$ \\
\hline$r, \cdot r$ &., 107. & $r, 00$ & $\varepsilon, \vee_{0}$ & IAT, Tr & 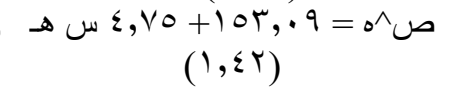 & 0 & الأولى & $\overline{3}$ \\
\hline$* 4,90$ &.,$r \wedge \vee$. & $7, \vee \leqslant$ & $19, .0$ & rAr,OQ & 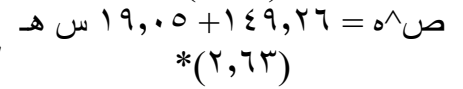 & 1 & الثانية & $\underline{\underline{\prime}}$ \\
\hline$* * \mid r \leq, .9$ &., $9 Y \leq$. & $\uparrow, \wedge \Lambda$ & 00,01 & $\Lambda \cdot \vee$ & 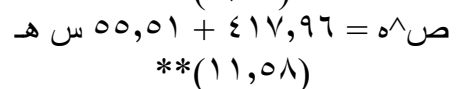 & V & الأولى & $\overline{x_{3}}$ \\
\hline **1or,o. & . & $0, r \mu$ & 10,10 & ITrV & 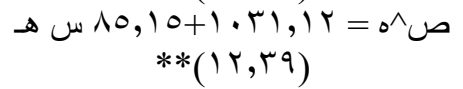 & $\wedge$ & الثانية & रे \\
\hline$* q, 0$. & . & $1, \pi 1$ & $1, \ldots$ & $V \Upsilon, r V$ & 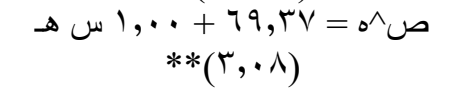 & 9 & الأولى & 腾 \\
\hline$\cdot, \vee \wedge$ & $\cdot, \ldots v \cdot$ & $(1,19)$ & $(1, \cdots)$ & $\wedge \varepsilon, \cdot r$ & 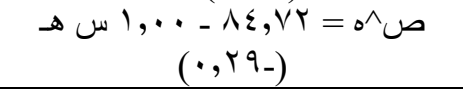 & 1. & الثانية & $\frac{\sqrt{7}}{3}$ \\
\hline
\end{tabular}

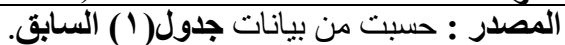

حيث أن: صدر : القيمة التقديرية للانتاج و الصادر و الوارد و الاستهلاك بالألف طن ونسبة الاكتفاء الذانى يالسنة ه. س هـ

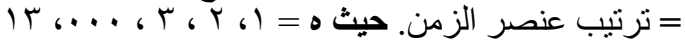

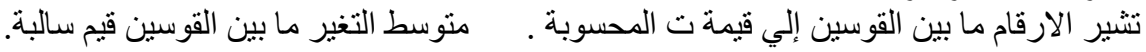

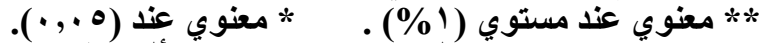

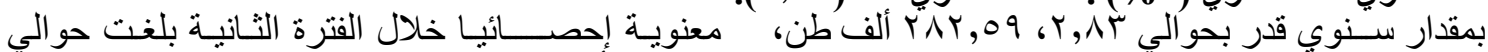

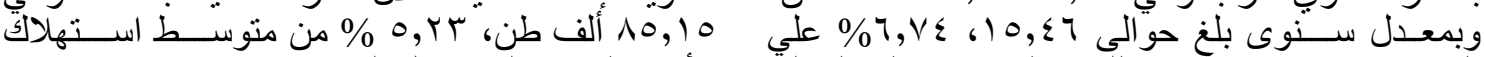

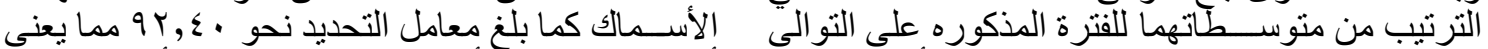

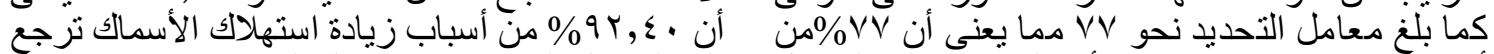

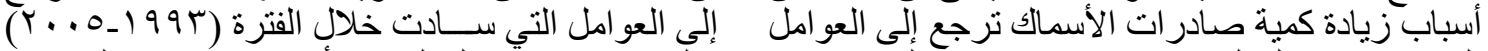

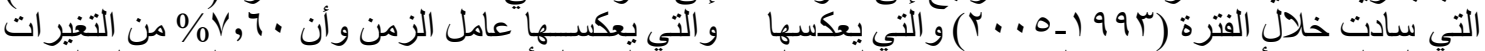

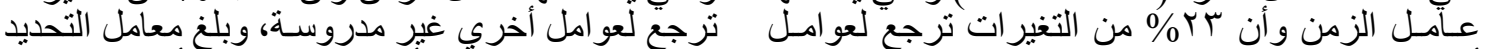

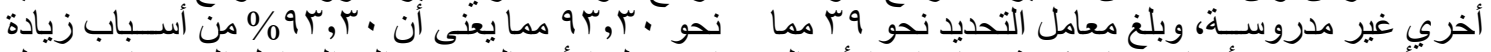

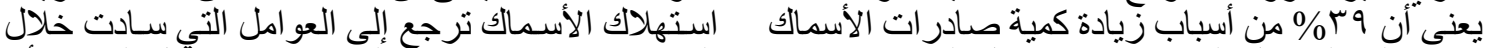

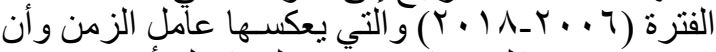

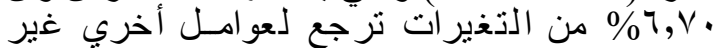

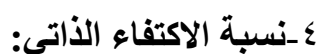

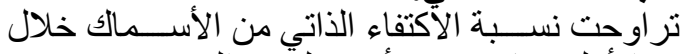

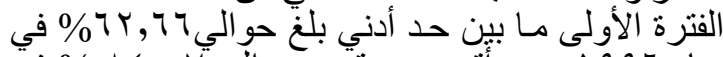

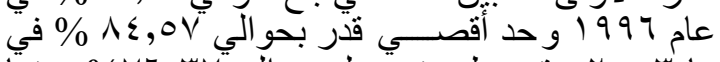

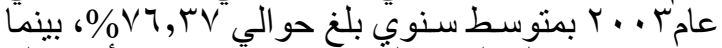

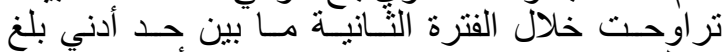

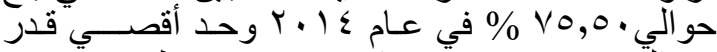

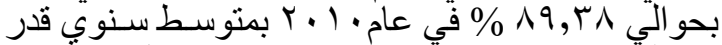

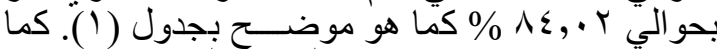

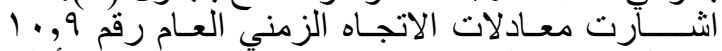

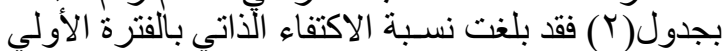

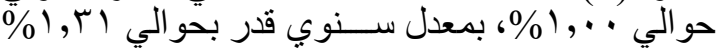

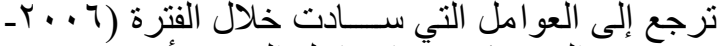

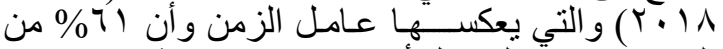
التغير ات ترجع لُعو امل أخري غير مدروسة.

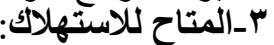

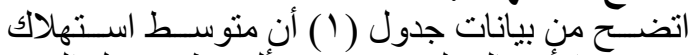

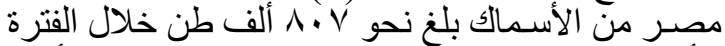

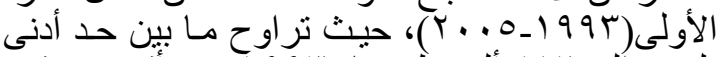

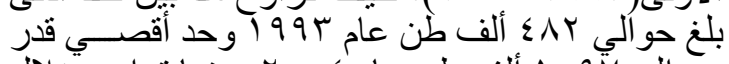

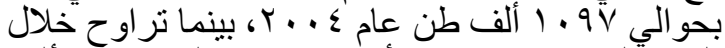

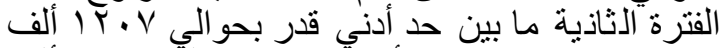

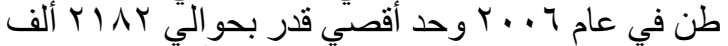

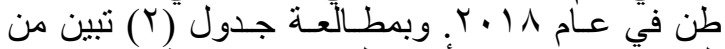

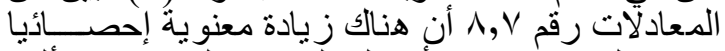

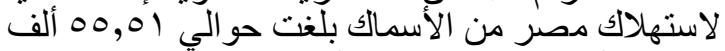

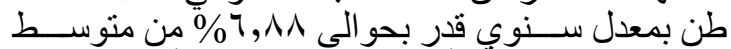
استهلاك مصر من "الأسماك خلاّل الفترة الأولى، وزيادة 


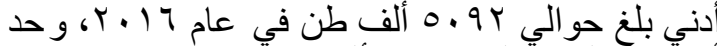

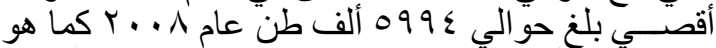

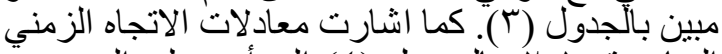

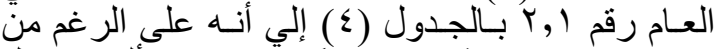

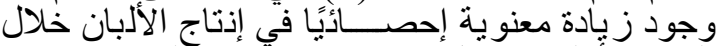

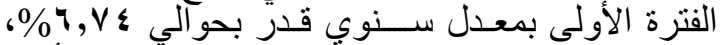

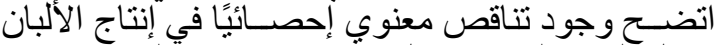

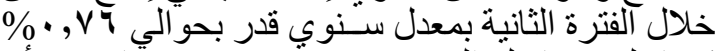

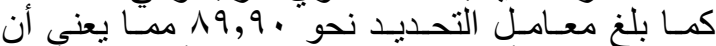

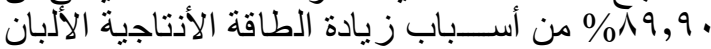

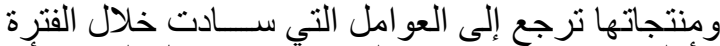

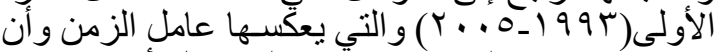

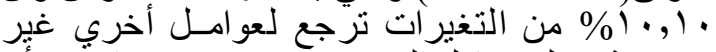

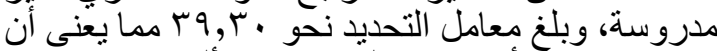

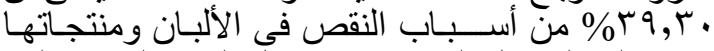

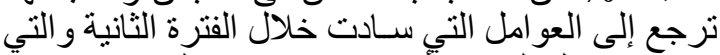

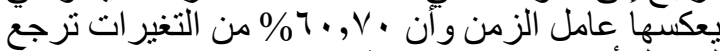
لعو امل أخري غير مدروسة.
من متو سط نسبة الاكتفاء الذاتي من الأسماك في مصر ، بكاك

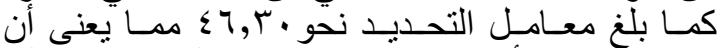

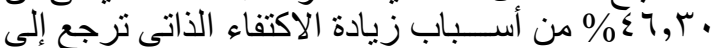

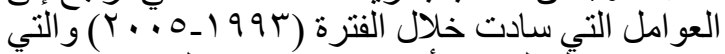

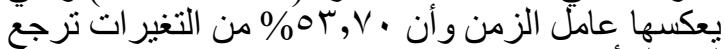

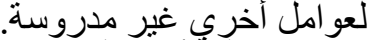

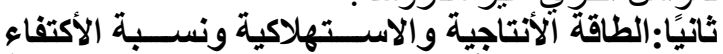

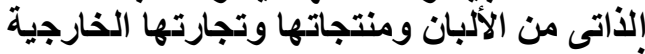

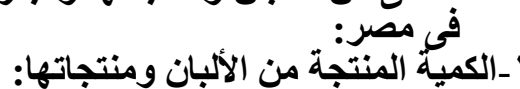

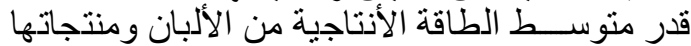

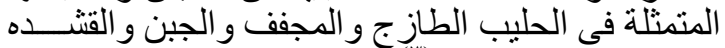

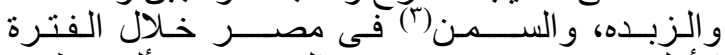

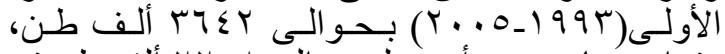

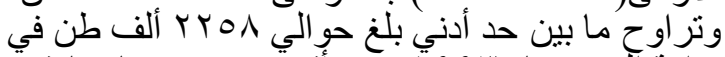

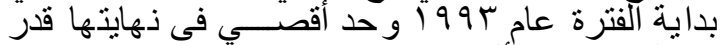

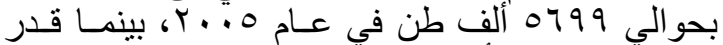

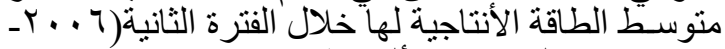

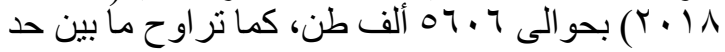

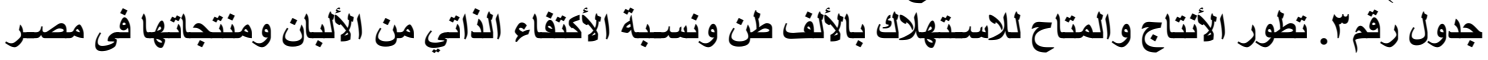

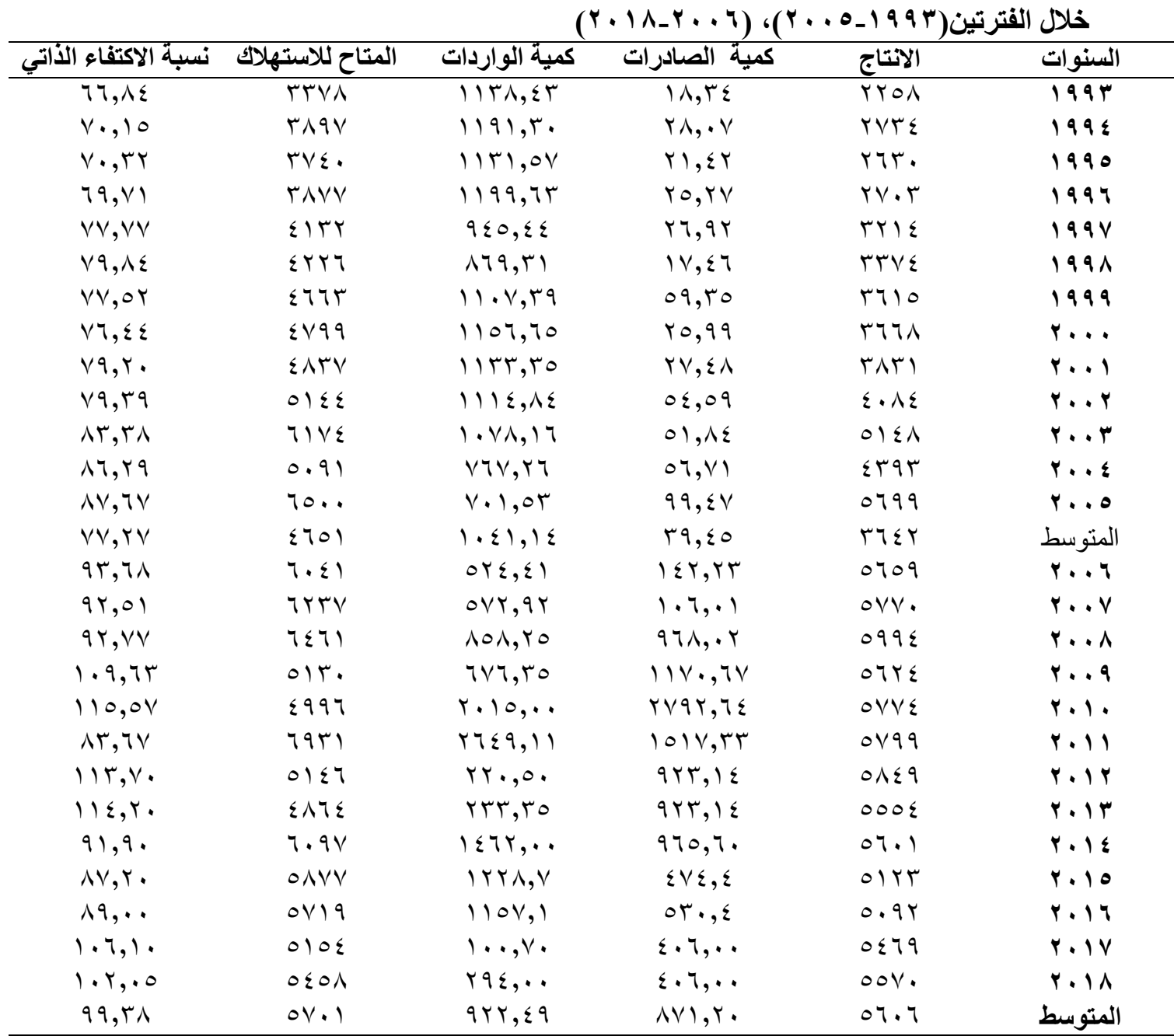




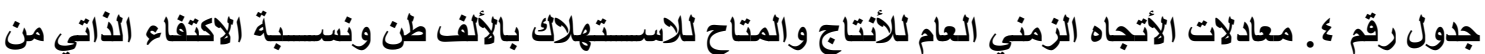

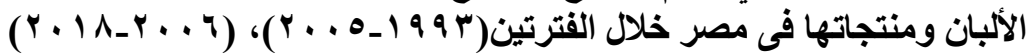

\begin{tabular}{|c|c|c|c|c|c|c|c|c|}
\hline فت & Y נ & التغير & متوسط & المتوسط & النموذج & p & الفترة & \\
\hline & & $\begin{array}{l}\text { المئوى } \\
\text { (\%) }\end{array}$ & (ألف طن) & & & & & \\
\hline $\begin{array}{c}* 9 \Lambda, \leqslant \varepsilon \\
*\end{array}$ & $\cdot, \wedge 99$ & $7, \vee \leq$ & $r \leq 0,01$ & $r 7 \leqslant Y$ & 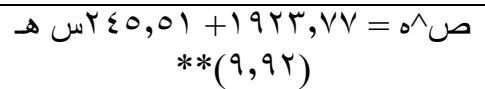 & 1 & الأولى & \\
\hline$* \vee, r$. & . & $(\cdot, \vee\urcorner)$ & $(\Sigma Y, O r)$ & 07.7 & 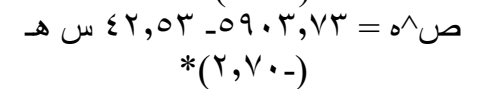 & r & الثانية & S \\
\hline$* 10,7 \mathrm{~V}$ &., $0 \wedge \wedge$. & $11, \wedge \varepsilon$ & $\varepsilon, T V$ & $r q, \varepsilon 0$ & $\begin{array}{c}ه ـ \varepsilon, T \vee+\neg, \vee q=ه \wedge ص \\
*(\Gamma, q \uparrow)\end{array}$ & $r$ & الأولى & $\overline{7}$ \\
\hline , Y. Y07 & . & $(\Gamma, 1 \tau)$ & $(Y V, O \cdot)$ & AYI, r. & 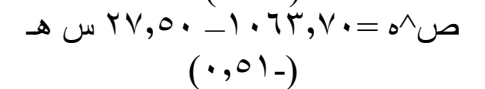 & $\varepsilon$ & الثانية & $\frac{3}{\sqrt[3]{3}}$ \\
\hline$* 0, \wedge \varepsilon$ &.,$r \leqslant \vee$. & $(Y, \Sigma \cdot)$ & $(Y \varepsilon, 9 \wedge)$ & $1 \cdot \leqslant 1,1 \leqslant$ & 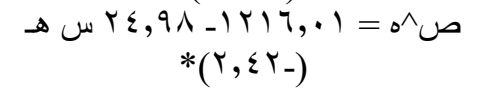 & 0 & الأولى & 2 \\
\hline ., IV. &., .10. & $(Y, T T)$ & $\left(Y \leq, Y_{0}\right)$ & $Q Y r, \leqslant 9$ & $\begin{array}{c}\text { ص } ه r \xi, r 0_{-}-1 \cdot 9 r, r r=\Delta \wedge \\
(\cdot, \Sigma)-)\end{array}$ & 7 & الثانية & $\frac{z^{\prime}}{\sqrt{3}}$ \\
\hline $\begin{array}{l}* \uparrow 9, r r \\
*\end{array}$ & . & $\varepsilon, \vee_{0}$ & $r r), \ldots$ & $\sum 701$ & 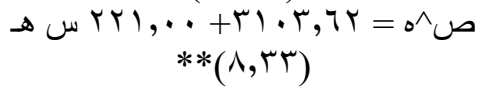 & v & الأولى & \\
\hline $1, r_{0}$ & $\cdot, 1 \cdot r \cdot$ & $(\cdot, 94)$ & $(O Y, Y T)$ & ov. 1 & 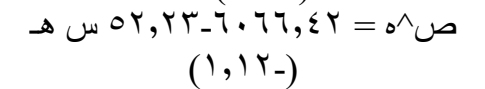 & $\wedge$ & الثانية & 芶 \\
\hline $\begin{array}{l}* \wedge \vee, r . \\
*\end{array}$ & $\cdot, \wedge \wedge \wedge$. & $r, \cdot r$ & $1,0 \mathrm{~V}$ & $V V, Y V$ & 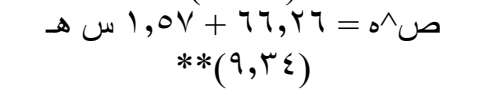 & 9 & الأولى & 率 \\
\hline$\cdot, .1 \varepsilon$ & $\cdot, \ldots 1$. & $(\cdot, 1 \cdot 0)$ & $(\cdot, 1, \varepsilon)$ & $9 ৭, \uparrow \wedge$ & 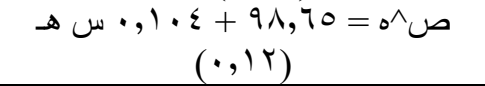 & 1. & الثانية & $\frac{7}{57}$ \\
\hline
\end{tabular}

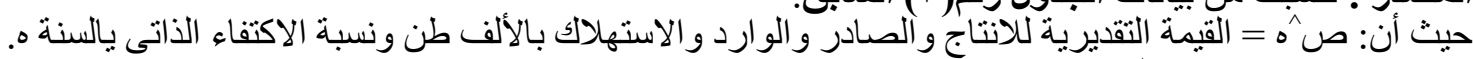

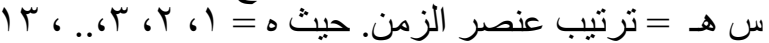
متوسط التغير ما بين القوسين قيم سالبة.

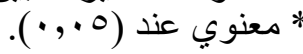

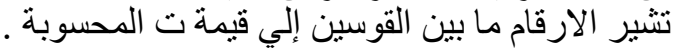

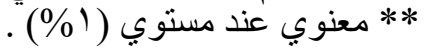

r-المتاح للاستهلاك من الألبان ومنتجاتها:

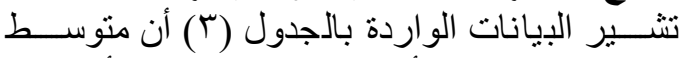

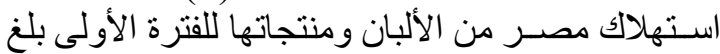

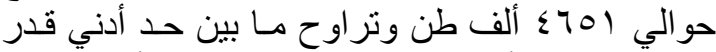

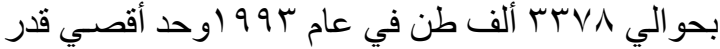

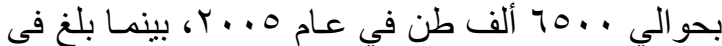

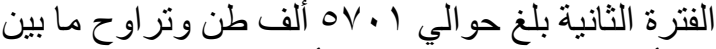

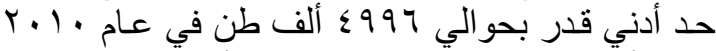

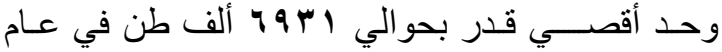

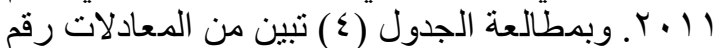

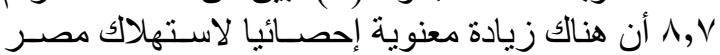

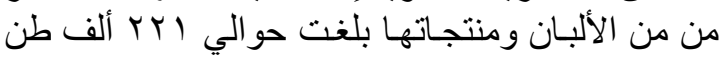

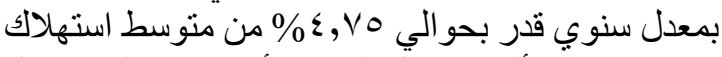

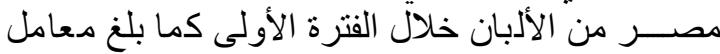

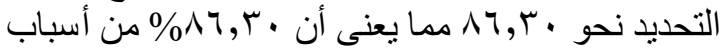

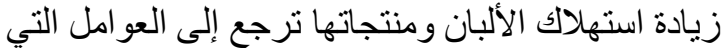

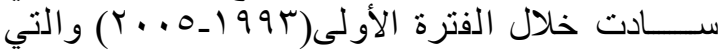

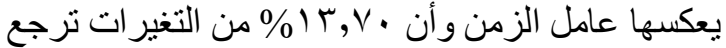
ل العوامل أخري غير مدروسة.
بـكمية الصادرات والواردات من الألبان ومنتجاتها في اتضــــح من الجدول (r) ســـالف الذكر نطور كمية

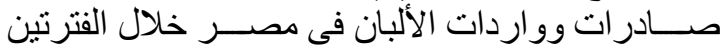

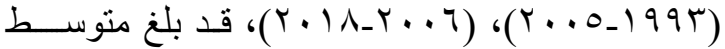

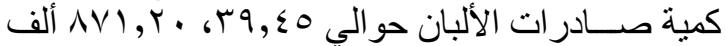

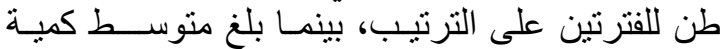

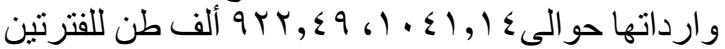

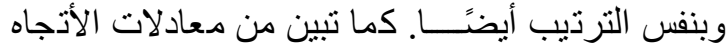

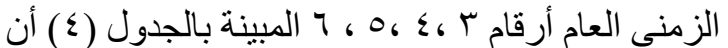

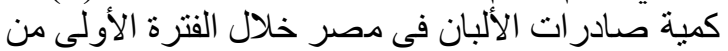

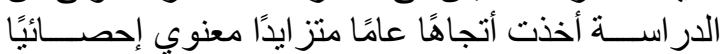

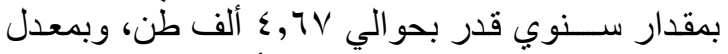

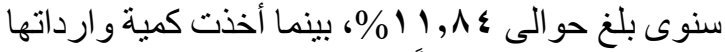

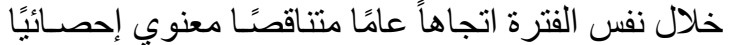

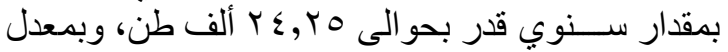

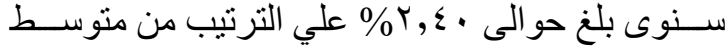
كمية الواردات للفترة المذكوره. 
نسبة الاكتفاء الذاتي الألبان ومنتجاتها ترجع إلى العو امل ولادي

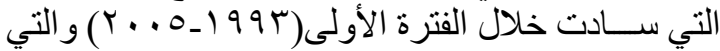

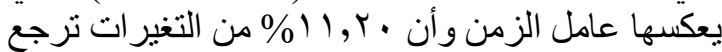

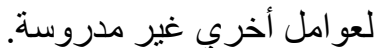

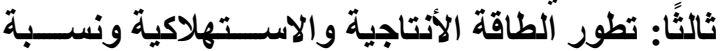

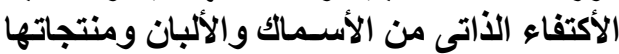

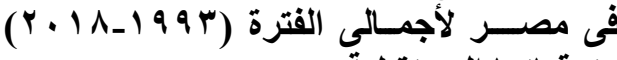

\section{وتوقعاتها المستقبلية:}

(أ) بتقدير معادلات الأتجاه الزمني العام لإنتاج الأسماك

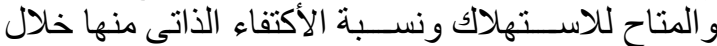

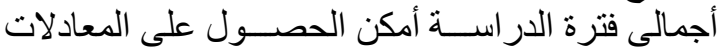

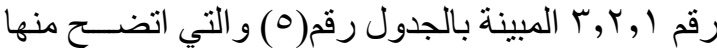

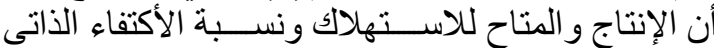

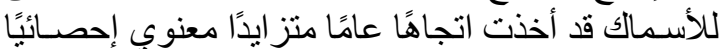

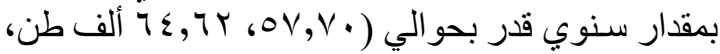

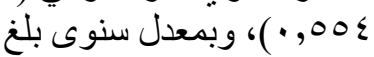

ع -نسبة الاكتفاء الذاتي من الألبان ومنتجاتها:

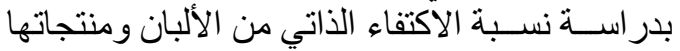

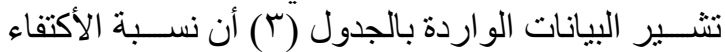

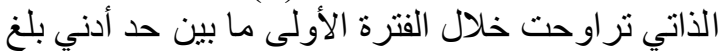

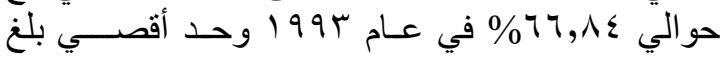

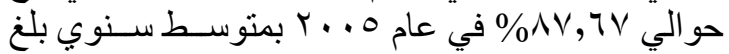

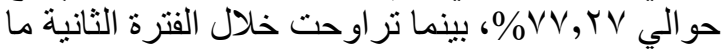

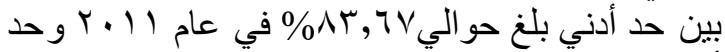

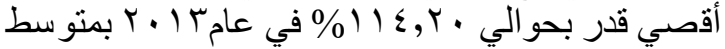

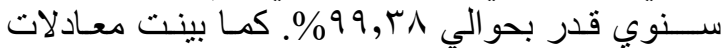

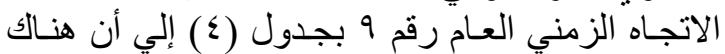

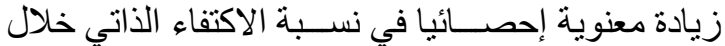

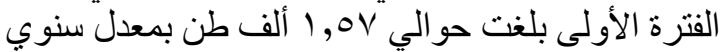

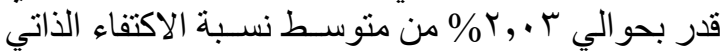

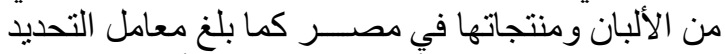

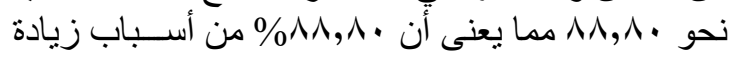

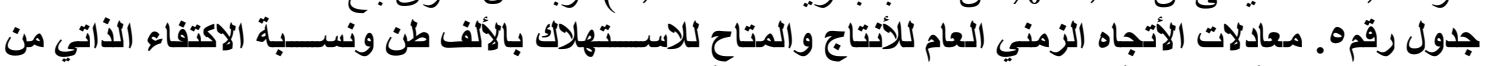

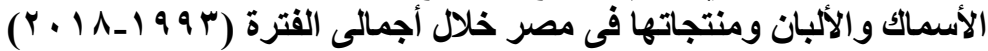

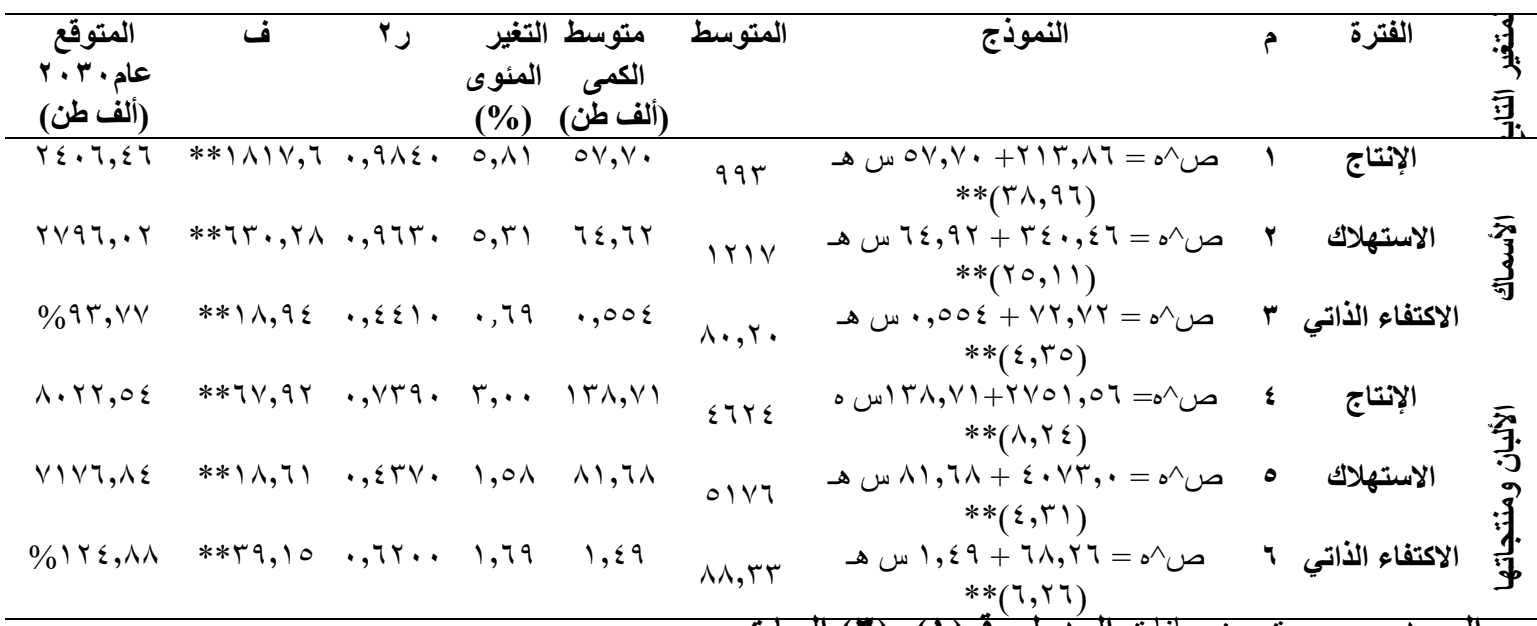

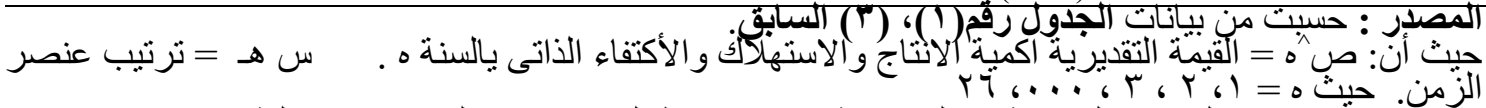

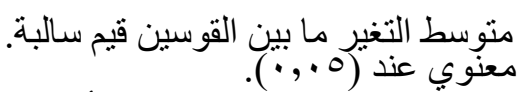

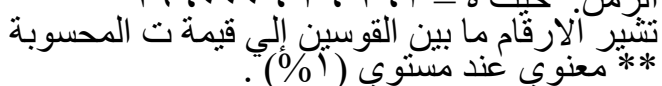
(ب) كما تبين من معادلات الأتجاه الزمني العام لإنتاج

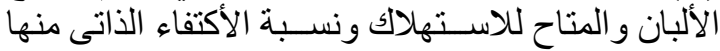

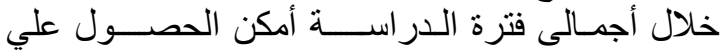

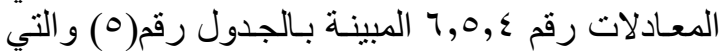

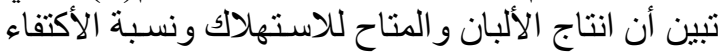

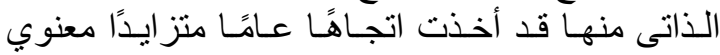

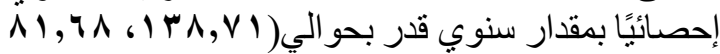

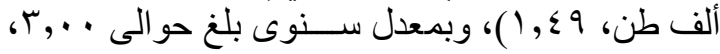

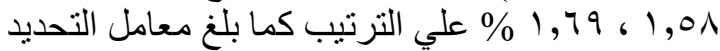

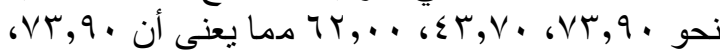
• ل

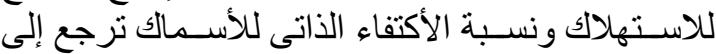

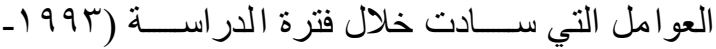

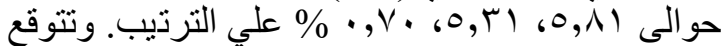

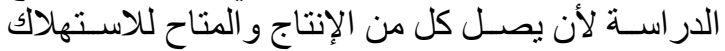

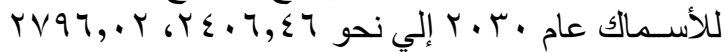

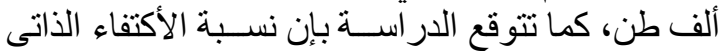

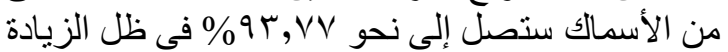

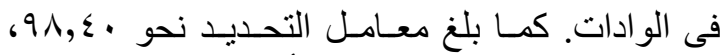

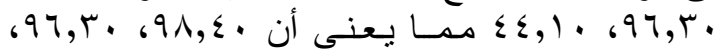

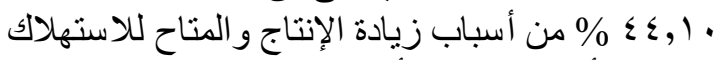

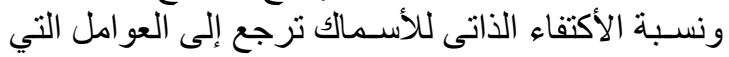

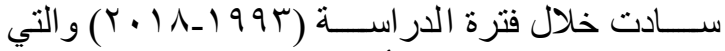

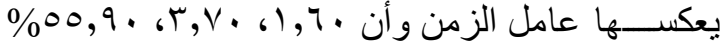
من التغير ات ترجع لعو امل أخري غير مدروسة. 


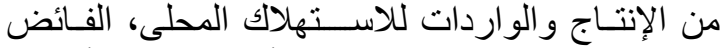

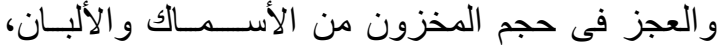
ومعامل الأمن الغذائى و التى تمثل قيمته نسبة الأني الأحر اف الفان أيجابًا أوسلبًا عن تحقيق الأنيق الأمن الغذائى.

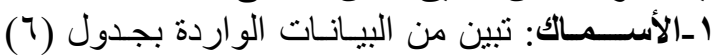

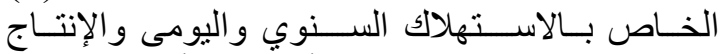

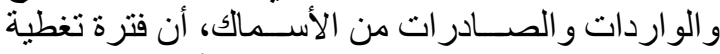

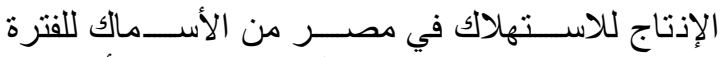

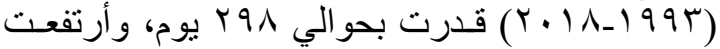

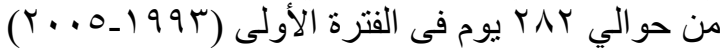

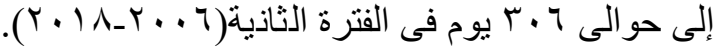

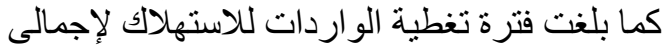

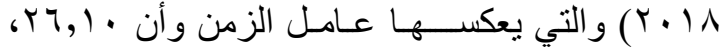

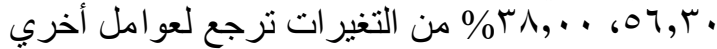
غير مدروسة. وتتوقع الدراسة لأن يصل كل مل من الإنتاج

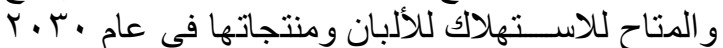

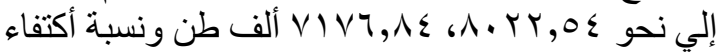

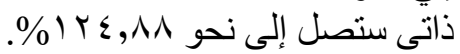
رابعًا: محددات الأمن الغذائي من الأســــــأك والألبان ومنتجاتها فى مصر :

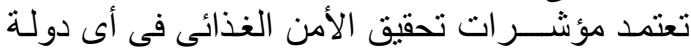

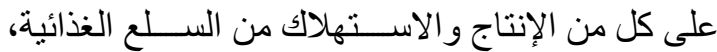

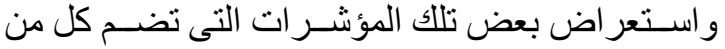

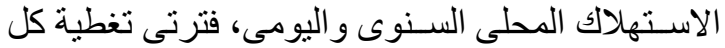

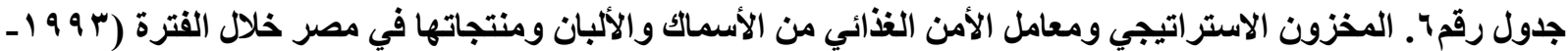

$(r \cdot 1 \wedge$

\begin{tabular}{|c|c|c|c|c|c|c|}
\hline & ل البان ومنتجان & & & الأسماك & & البيان \\
\hline 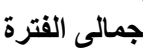 & لفترة الثانية & لفترة الأولى & بمالى الفتر & لفترة الثانياً & الفترة الأولى & \\
\hline$-(994)$ & $-r . .7)$ & $-(994)$ & $-(994)$ & $-r \ldots q)$ & $-(994)$ & \\
\hline$(Y \cdot 1 \Lambda$ & $(r+1 \Lambda$ & $(r \ldots o$ & $(r+1 \Lambda$ & $(Y+1 \Lambda$ & $(Y \ldots o$ & \\
\hline $01 \times 7$ & ov. 1 & $\leqslant 701$ & IYIV & ITYV & $\Lambda \cdot V$ & الاستهلاك السنوي (ألف طن) \\
\hline $1 \leqslant, 11$ & $10,7 r$ & $M, V \varepsilon$ & 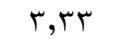 & $\leqslant, \leqslant 7$ & $r, r_{1}$ & الاستهلاك اليومي (ألف طن) \\
\hline$\leq \pi Y \leq$ & 07.7 & $r า \leq r$ & ११५ & מדומו & Trt & كمية الإنتاج (ألَف طن) \\
\hline 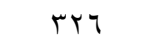 & ro9 & YAт & rqA & $r .7$ & rAT & فترة تغطية الإنتاج للاستهلاك (باليو م)( (1) \\
\hline $9 \wedge 1, \wedge r$ & $q r r, \leqslant q$ & $1 . \leqslant 1,1 \leqslant$ & $r r \varepsilon, \leqslant 7$ & rAr,, 09 & ו & متوسط كمية الواردات (ألف طن) \\
\hline 79 & 09 & $\wedge r$ & $v \cdot$ & זי & $\wedge \varepsilon$ & فترة تغطية الو اردات لكلاستهلاكك(باليوم)(r) \\
\hline rqo & $\leq 1 \wedge$ & rus & rus & rาq & 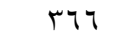 & 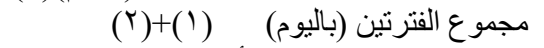 \\
\hline س & $\Delta \vee 1, r$. & ५ , ऽ० & $1 \cdot, r \varepsilon$ & $|\wedge, \Gamma|$ & r tra & متوسط كمية الصنادر ات (ألف طن) \\
\hline$\left(Y_{0,01}\right)$ & $(\varepsilon r, \vee l)$ & $(\vee, r)$ & $\cdot, I r$ & $\cdot, r \wedge$ & $(\cdot, \cdot \varepsilon)$ & 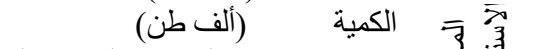 \\
\hline$(1, \wedge \cdot)$ & $(\uparrow, \wedge \cdot)$ & $(\cdot, \circ \vee)$ & $\cdot, \cdot \varepsilon$ & $\cdot,+7$ & $(\cdot, \cdot r)$ & فترة كفاية المخزون للاستهلاك \\
\hline
\end{tabular}

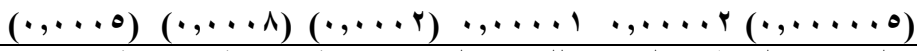

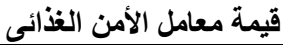

المصدر: جمعت وحسبت من: جامعة الدول العربية، المنظمة العربية للتنمية الزر اعبة، الكتاب السنوي للإحصاءات الأرقام مابين القوسين تشير أن

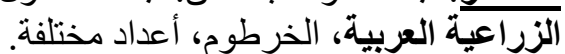

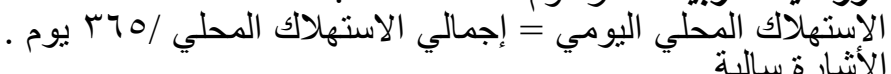

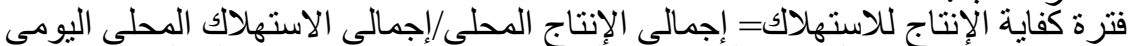

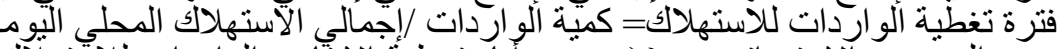

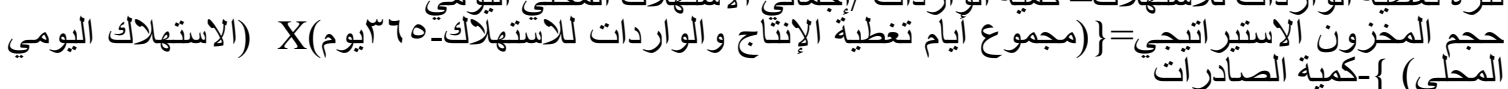

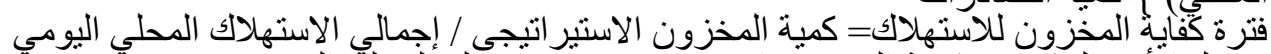

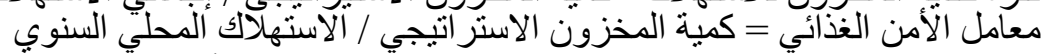

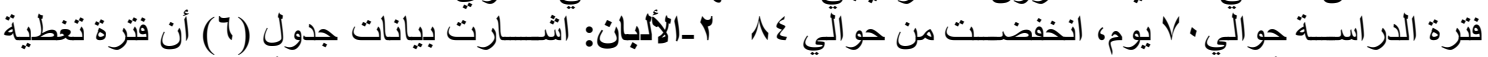

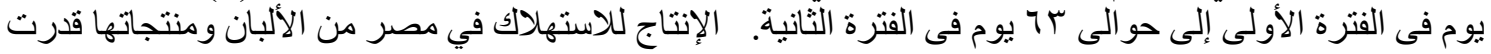

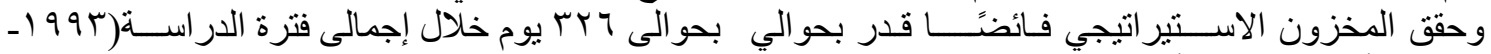

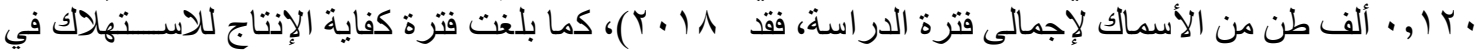

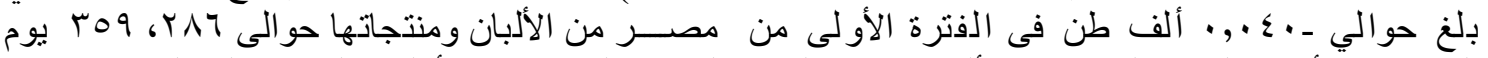

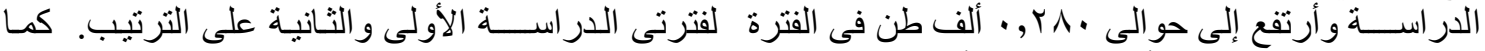

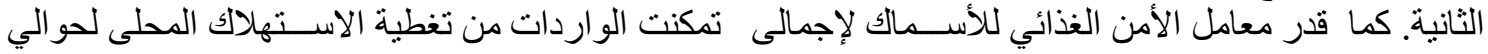

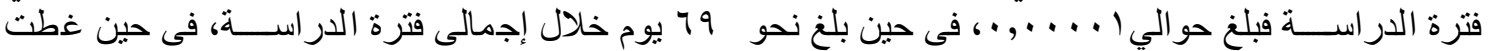

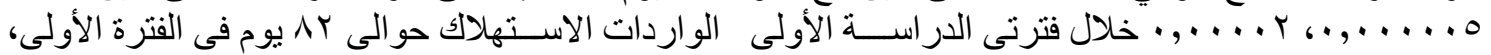

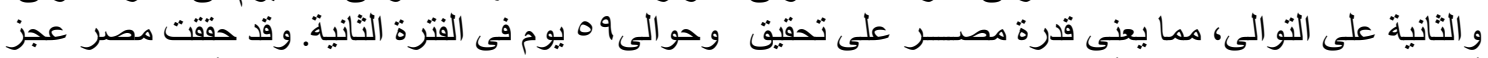

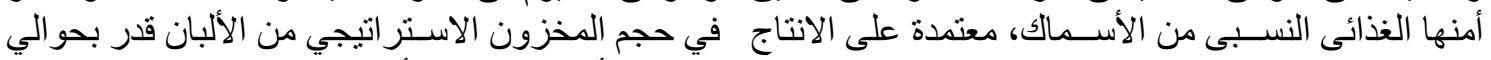

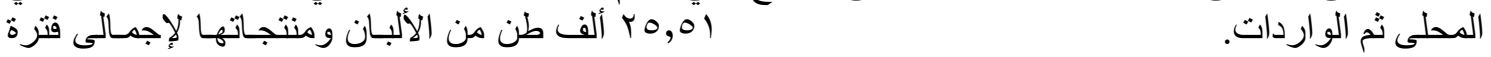




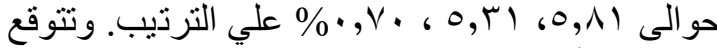

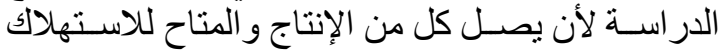

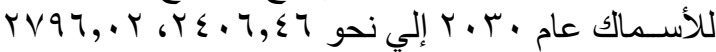

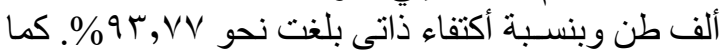

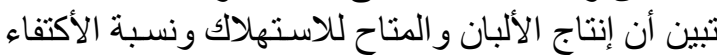

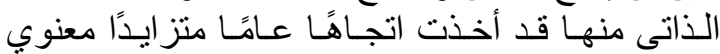

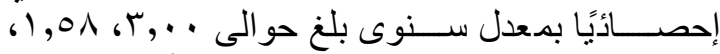

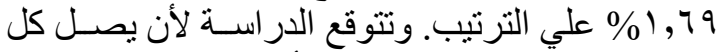

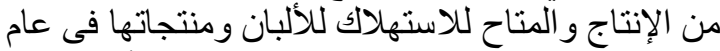

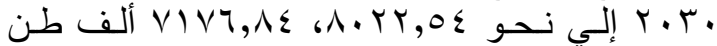

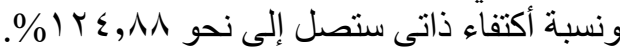

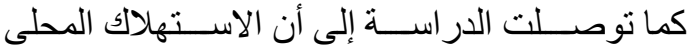

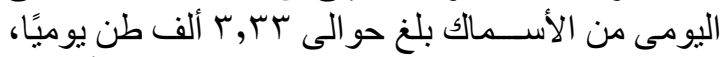

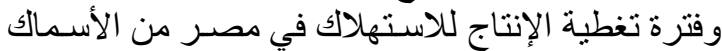

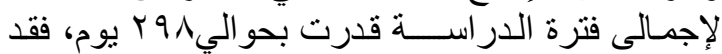

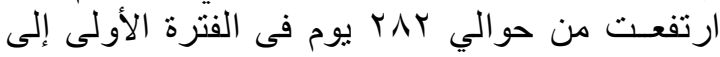

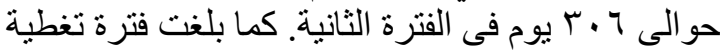

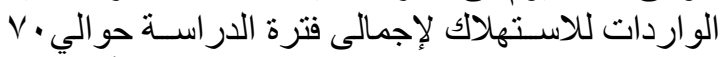

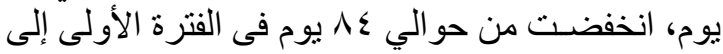

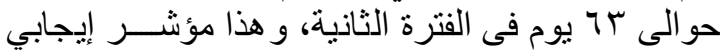

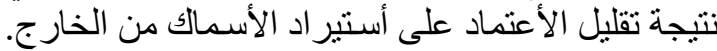

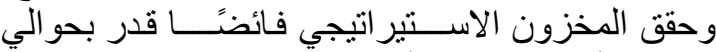

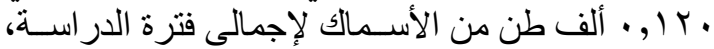

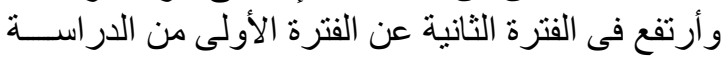

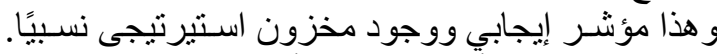

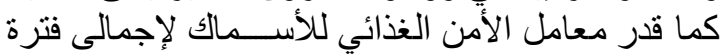

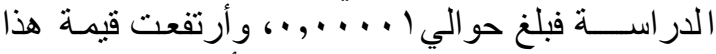

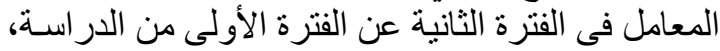

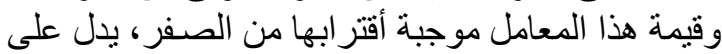

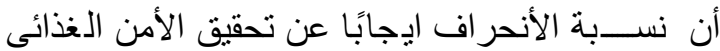

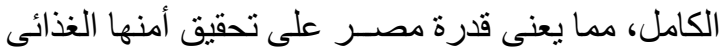

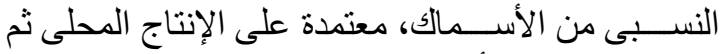

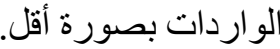

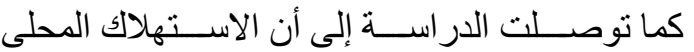

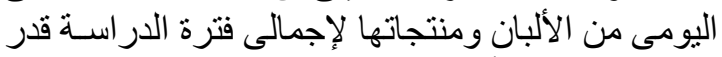

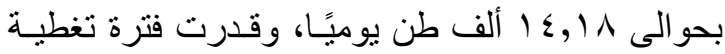

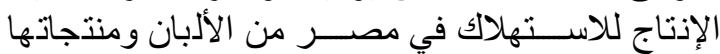

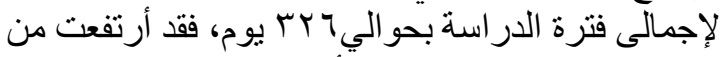

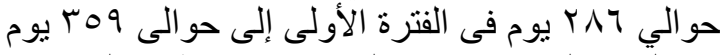

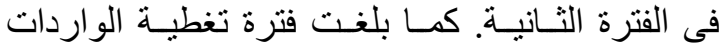

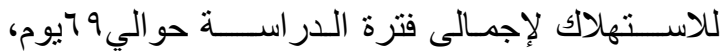

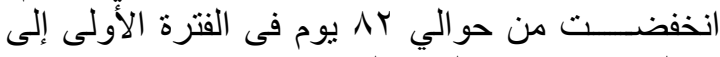

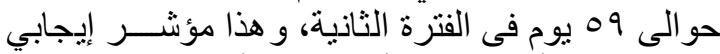

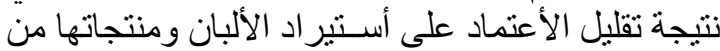

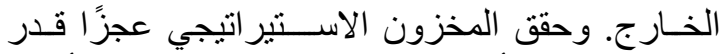

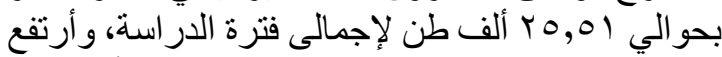

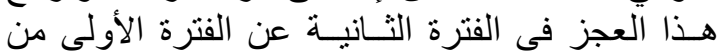
الدراســة، وهذا مؤشــر سـلبى نتيجة زيادة الفجوة بين الاولين

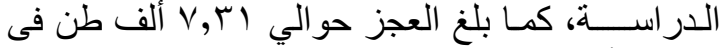

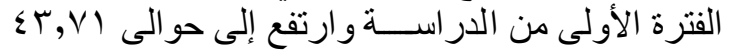

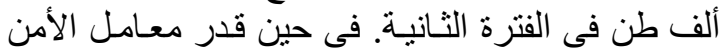

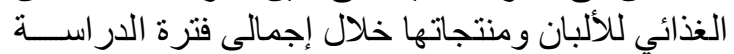

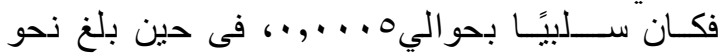

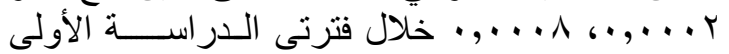

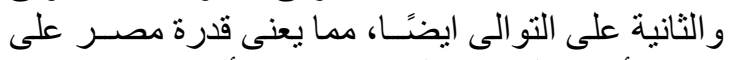

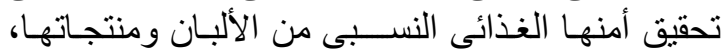

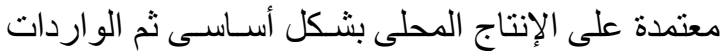

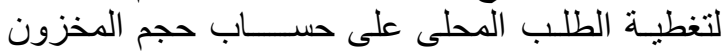
الاستير اتيجى من الألبان.

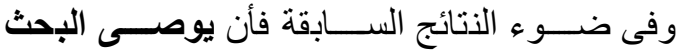

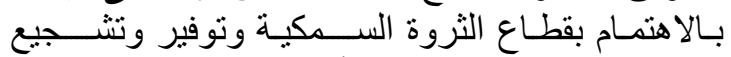
الاستتمار في مجال مز ارع الأسماك و والحئ الحيو اناتات المنتجة

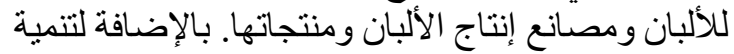

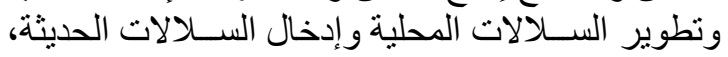

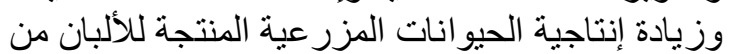

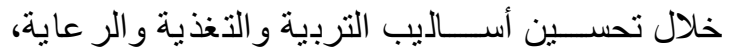

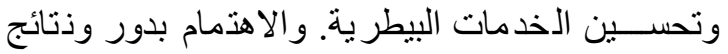

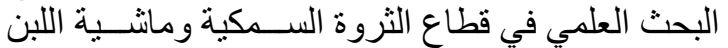

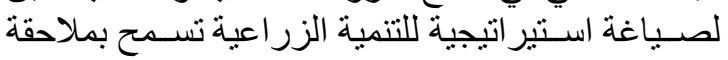

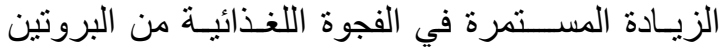

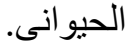

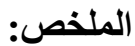

تعتبر الأســـماك و الألبان ومنتجاتها من المصـــــادر

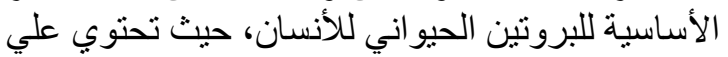

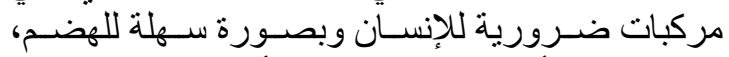

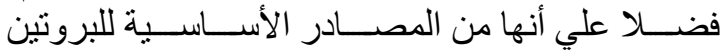

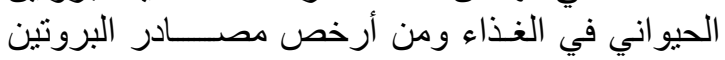

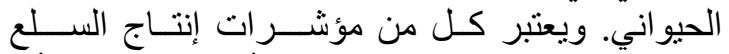

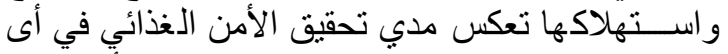

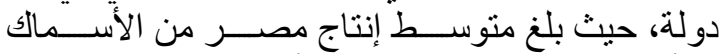

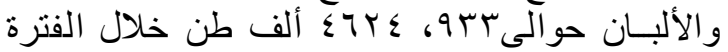

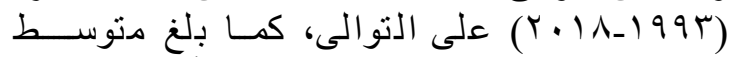

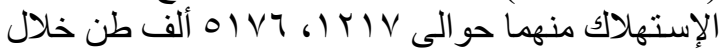

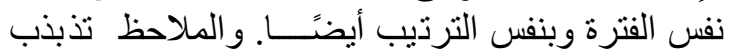

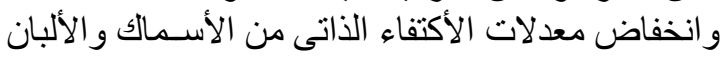

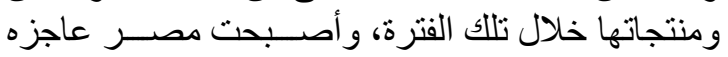

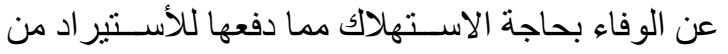

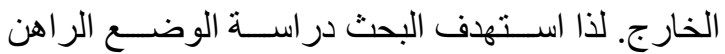

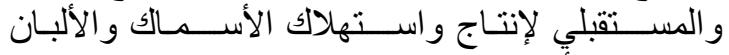

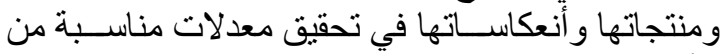

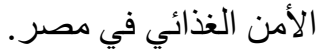

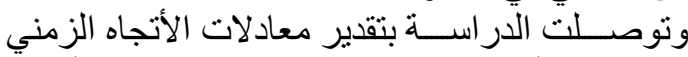

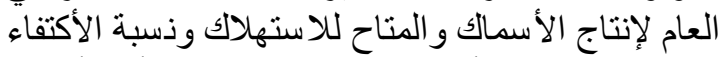

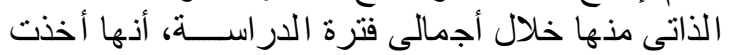

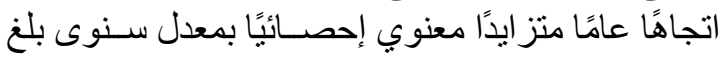




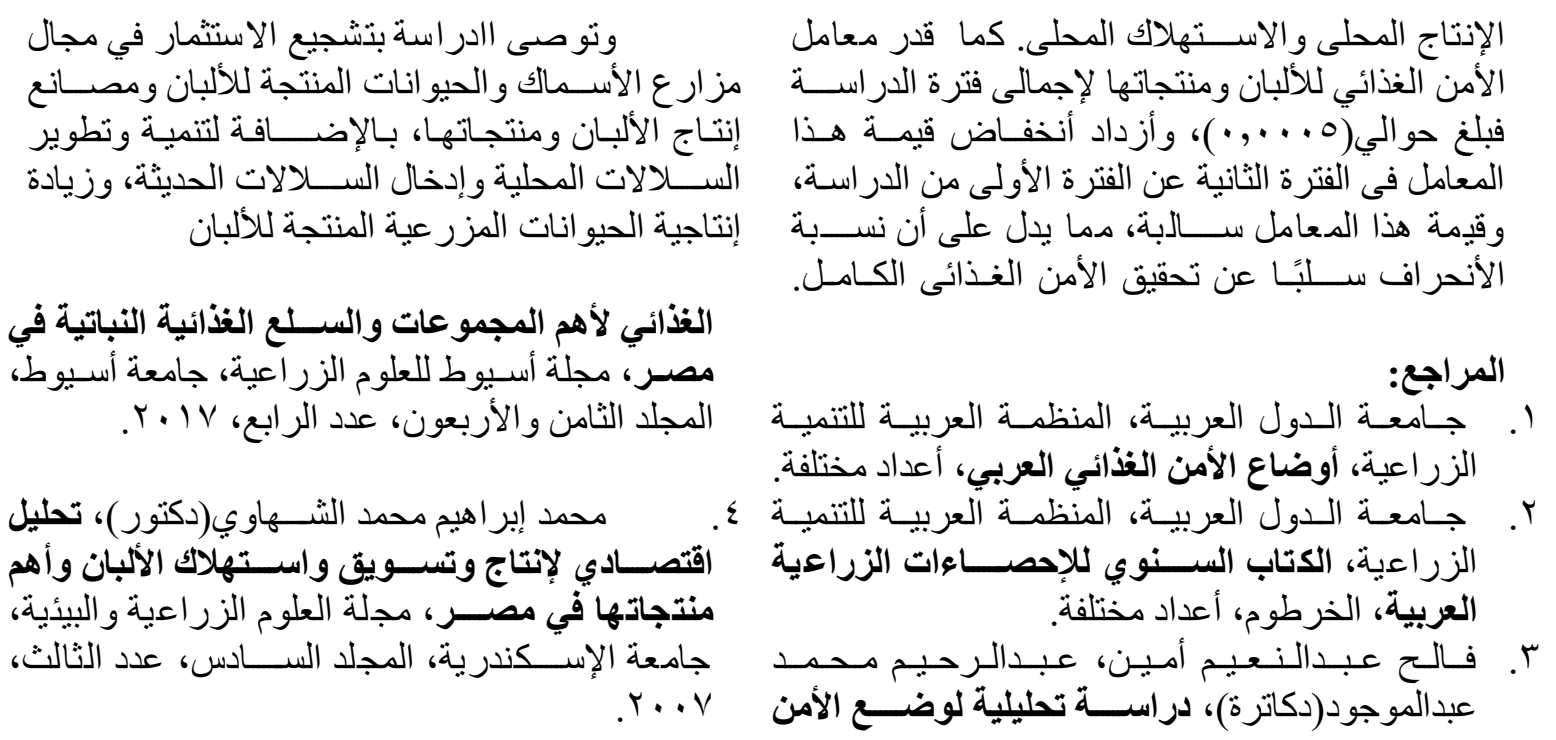

\begin{abstract}
Fish, milk and its products are considered one of the main sources of protein for humans, as they contain compounds necessary for humans and in an easy-to-digest manner, as well as one of the main sources of animal protein in food and one of the cheapest sources of animal protein in Egypt if compared to other sources of animal protein. Each of the indicators of commodity production and consumption reflects the extent of achieving food security in any country, as Egypt's average production of fish and milk reached about 933, 4624 thousand tons during the period (1993-2018) respectively, and the average consumption of them reached about 1217,5176 thousand tons. During the same period and in the same order as well. It is noticeable that the rates of self-sufficiency in fish, milk and their products fluctuated and decreased during that period, and Egypt became unable to meet the consumption needs, which prompted it to import from abroad. Therefore, the research aimed to study the current and future status of the production and consumption of fish and milk products and their implications for achieving adequate levels of food security in Egypt.

The study concluded by estimating the equations for the general temporal trend of fish production and available for consumption and the percentage of self-sufficiency from them during the total study period, that it took a statistically significant increasing general trend at an annual rate of about 5.81, 5.31, and $0.70 \%$, respectively. The study expects that in 2030 , the production and available for consumption of fish will reach about 2406.46, 2796.02 thousand tons, with a self-sufficiency rate of about $97.77 \%$. It was also found that the production of dairy and available for consumption and the self-sufficiency ratio took a general, statistically significant increasing trend at an annual rate of about 3.00, 1.58 and $1.69 \%$, respectively. The study expects that the production and available consumption for milk and dairy products in 2030 will reach about 8022.54, 7176.84 thousand tons, with a self-sufficiency rate estimated at $124.88 \%$.

The study also found that the daily local consumption of fish amounted to about 3.33 thousand tons per day, and the period of covering production for consumption in Egypt of fish for the total study period was estimated at about 298 days. It increased from about 282 days in the first period to about 306 days in the second period. . The period of coverage of imports for consumption for the total study period was about 70 days; it decreased from
\end{abstract}


about 84 days in the first period to about 63 days in the second period. This is a positive sign as a result of reducing dependence on importing fish from abroad. The strategic stock achieved a surplus estimated at about 0.120 thousand tons of fish for the total study period, and it increased in the second period over the first period of the study. This is a positive sign and the presence of a relatively strategic stock. The fish food security coefficient for the total study period was estimated at about 0.00001 , and the value of this factor increased in the second period compared to the first period of the study, and the value of this factor is positive, approaching zero, indicating that the percentage of deviation is positive from achieving complete food security, which means the ability Egypt to achieve its relative food security of fish, relying on local production and then imports to a lesser extent.

The study also found that the daily local consumption of milk and dairy products for the total study period was estimated at about 14.18 thousand tons per day, and the period of production coverage for consumption in Egypt of milk and dairy products for the total study period was estimated at 326 days, as it increased from about 286 days in the first period to about 359 days in the second period. The period of coverage of imports for consumption for the total study period was about 69 days; it decreased from about 82 days in the first period to about 59 days in the second period. This is a positive sign as a result of reducing dependence on importing milk and dairy products from abroad. The strategic reserve achieved a deficit estimated at about 25.51 thousand tons for the total study period, and this deficit increased in the second period compared to the first period of the study, and this is a negative indicator as a result of the increase in the gap between local production and domestic consumption. The food security factor for milk and dairy products for the total study period was estimated at about (0.0005), and the value of this factor increased in the second period compared to the first period of the study, and the value of this coefficient is negative, which indicates that the percentage of deviation is negative from achieving complete food security. 